\title{
THE POSTINDUSTRIAL SOCIETY, SCIENCE AND PROFESSIONS
}

Our main aim is to characterize the settlement and mutations of theories of professions using also other than traditional sociological approaches to this issue. Above all, we have been inspired by conceptions formed in the area of science and technology studies. The main argument appears from the fact that enquiry into professions can possible lead to description of important mutation that characterizes the scene of work and class-divided composition of "postindustrial society".

\section{Introduction}

Information society, postindustrial society, knowledge society: these are the titles of our times which have rooted strongly in the language when we talk about current situation. Perhaps this is the result of the need of our mind to know where we are, to find our here and now or to define ourselves somehow in order to know us. Maybe these terms are just resulting from modernist efforts to constantly supersede something, aiming forward. From industrialism to postindustrialism and after even further to another "post" which we will find in our way through history.

Definitely, this is one of possible elevations on postindustrialism. Indeed, it has to be taken into account that postindustrialism is rather theoretical concept than real situation. Daniel Bell, we could say the godfather of this concept, says: "The Idea of postindustrial society is not a point-in-time prediction of the future but a speculative construct" [1]. It is quite interesting to watch how this speculative construction has (together with Information society or Third's wave society prediction) transformed into the appearance of objective fact as the mark to which each society should lead up. At least, this is the way, which is presented in many political talks. We understand this concept as an expression of changing nature of some aspects of public life. But, this does not mean that we automatically regard the present state as equal to the one natural to the concept of postindustrialism. However, it is not the content of this article to describe postindustrial society as an ideal type or objective fact. Max Weber says about ideal types that "are concerned as virtual structures that are created to help us understand the particularity of real course of events. The ideal type is created by unilateral mental enforcement of one ore more respects of examined event and its rational perfection into integrated abstract mode." [4]

Our main aim is to characterize the settlement and mutations of theories of professions using also other than traditional sociological approaches to this issue. Above all, we have been inspired by conceptions formed in the area of science and technology studies.

Why especially the matters of professions which have already seemed to be not topical and lifeless? "The decline and near disappearance of papers on the profession would make it appear that this category of occupation is no longer meaningful to sociologists" [2].

Our main argument appears from the fact that enquiry into professions can possible lead to description of important mutation that characterizes the scene of work and class-divided composition of "postindustrial society". Or, rather: "Studies of profession clearly illustrate the intricate interplay between general conceptions of society and history, sociological theory, definitions of social categories, empirical research and political values." [3] As the important mutation we chiefly understand the increase of number of jobs and occupations which are based on some scientific knowledge or are directly defined as scientific. Manager, physician, scientist, lawyer, engineer, pharmacist, these all are such types of jobs, while in terms of sociology these jobs could be assigned as professions. It is exactly ideology (We understand ideology the same way as sociology of knowledge does - it is the translation of world, narration about world and everydayness. Each of us has some type of ideology; economic, sociological or political) pushed by concept of postindustrialism (or "information society") that is the main source that have lead us to support their further development and regarding this development as natural.

As first, we point at sociological traditions and paradigm used while analyzing the phenomenon of professions. As it is customary of social science there is an absence of unity about what exactly is the part the professions play in society. Functionalistic approaches inspired by T. Parsons regard professions as the main source of changes in advanced society. Vice versa, neoweberian tradition considers professions as units that are able to monopolise the influence over certain field of knowledge or praxis. From this point of view

\footnotetext{
* Roman Hofreiter

Department of Pedagogy, Psychology and Social Science, Faculty of Science, University of Zilina, E-mail: roman.hofreiter@fpv.utc.sk
} 
the professions are units that separate experts from layman. Besides these traditional approaches, we try to mention alternative ways of understanding professions which have been created in last two decades in field of science and technology studies (B. Latour, J. Law, Knorr- Cetina, M. Michael etc.) as they could refresh the studies on professions.

\section{Naivism or Cynicism?}

What exactly is the profession? Which work can we call profession and which we cannot? What is the role of professions? These all are the questions possibly connected to our subject. However, there is a problem as they all are associated with just one sociological approach to the professions, with the structural functionalism. But, there exists also another sociological tradition which introduces different questions. How do the professions obtain their extraordinary rank in the social structure? (Larson) What are sources of their influence? (Friedson) How do they use this extraordinary rank in the society?

Thomas Brante called these different approaches tropologically as naivism and cynism. We accept this labeling as characteristic for different approaches.

So what characterizes the naivistic approach to profession? To settle this matter we have to take a look at some thoughts of Talcott Parsons. It seems necessary to begin with Parsons' thought on modernity. It emerges from traditional "enlightened conception of progress" [5] and formalizes evolutionistic theory of history. "Society progresses from simpler to more complex forms. The complexity is result of structural differentiation which is source of increased specialization and division of labour"[3]. This process means inter alia tradition redemption and consistent transition to universal and rational modalities. Thus, modernity is not result of specific type of economic order, which includes capitalism, free enterprise or business economy. For him it is a result of achieving certain type of rationality which is strongly interwoven into institutional pattern of contemporary society and which falls back on values like universalism, specificity and applied scientific knowledge. This is the evidence of strong Parsons' inspiration in Weber's theory of rationality. Weber uses the concept of rationality as an instrument that is able to explain performance of an individual in certain time and certain place. The system of religion represents specific form of rationality - value oriented rationality, while capitalism is purpose-built rational performance.

And, main carriers or types of values of modernity respectively, are professions. "It seems evident that many of the most importance features of our society are to a considerable extent dependent on the smooth functioning of the professions." [6]

A first important value for him is "the applied scientific rationality". However, it needs to be mentioned that Parsons does not understand this kind of rationality in pure technical sense like a science transferred into living. Rather they are proceedings inspired by practices that are applied in science. The emphasis is on func- tionally rational decisions which are in possible conflict with traditions. It pushes on objective standardization of approaches dedicated to find the best solution. Consequently, the applied scientific rationality refers not only to scientific and technical professions but also to much performance of latter society. "The business man, the foreman of labor, and not least the non-scientific professional man such as the lawyer, is enjoined to seek the "best", the most "efficient" way of carrying on his function, not to accept the timehonored mode."[7]

The second important value for smoothly functioning of modern societies is specificity of function. This means that authority of professions is applied only to specific scene of knowledge and practice and is not an outcome of their generally superior status. This authority grows out of applying applied scientific rationality on a given scene. This specificity of function is also essential to another crucial pattern of our society, for example, all administrative offices or business economy. According to Parsons, the professional mode of work is the key pattern of such set-up of authority, which is behind rational and bureaucratic management of contemporary society.

The third important value for organization of modern industrial societies is universalism as an opposition against particularism. Parsons writes:"The standards and criteria which are independent of the particular social relationship to a particular person may be called universalistic; those which apply by virtue of such a relationship on the other hand are particularistic"[6]. Scientists do not work just because of their own good as well as physicians do not remedy merely their relatives. It is particularly universalism or orientation on collective goals that makes the difference between professions and other jobs and occupations. But this is just a surface. The concept of universalism has become typical for the whole occupational system whose status is largely independent from status in kinship groups, religion, or as sociologists say: the primary group relationships.

Following all the mentioned values Parsons assumes that professions are specific institutional frameworks that are standing behind modern institutions like science, education and their practical use in technology, medicine, management and governance. His view on professions has for large number of followers of functionalistic paradigm in sociology become a universal base to this issue. Professions were understood as a real self-contained subsystem of work system and then, main task was just to specify certain criteria to separate them from other occupations in work system. As a example of this pradigmatic approach to the problem of proffesion see papers of an important Slovak sociologist of work Ján Pichňa. An essential example is Millerson's enumerative definition of profession. 1. The use of skills based on theoretical knowledge; 2. education and training in these skills; 3 . competence of proffesionals is ensured by examinations; 4 . a code of conduct to ensure professional integrity; 5 . performance of service that is for the common good; 6 . a professional activity which organizes its members. [3]

Besides, we can also find similar assumptions to these of $\mathrm{T}$. Parsons' in works of some theorists of transformation of industrial 
society, especially in Daniel Bell's postindustrialism. The base of the variation is or will be growth and development of theoretical expert's knowledge. Scientists, computer experts, economists and other experts in postindustrial society, represent not merely a new technology but also a new technocratic ideology in society which will replace standing political ideology. The society will be taken over by expert's knowledge and technocratic solutions stemming from scientific approach hence used solutions should be better and more efficient.

Pursuant to the all mentioned it is very simple to judge why Brante entitles this paradigm as naivism. An idealized picture of science and its rules as objective and established universally forms idealized image of professions whose position is above all based on using applied scientific rationality. According to an evolutionistic conception of social development, it is assumed that professions are necessary component of this process.

However, each paradigm is disposable until its ultimate assumptions are able to answer the emergent issues. "Idealized fundamentals" of this approach are exactly the cause of the fact that after some time they could not serve as basis of research on professions and it was necessary to look for another resource.

Another approach refusing Parsons' idealism is the combination of symbolical interactionism ${ }^{1)}$ and neoweberian traditions in sociology. Thomas Brante called it cynicism. What is the source of difference of this look on professions? Talcott Parsons has taken the technical, social, cultural and ideological achievement of the successful professional groups, as it was a natural historical fact about modern society. According to E. C. Hughes this was also the source of false question: "Is this occupation a profession?" After him the following question is much preferable: "What are the circumstances in which people in an occupation attempt to turn it into a profession and themselves into professional people? [2]" So it is not eligible to take professions as "social object" or noun but accept them as "social process" or the verb instead and watch what professions actually do in everyday life to negotiate and maintain their special position, how they become a profession or better the process of professionalization. Because of the lack of space we cannot analyze the whole spectrum of explanations offered by several authors of this paradigm (Friedson, Larson, Hughes, Becker etc.). So as the explanation we use the ideal type of this approach that we design towards power, closure and Professional ideology.

Here, the power is associated with its weberian tradition as a means which groups and individuals enforce and support their own interests and ideologies in society. Indeed, this does not mean that the professions do directly use some kind of pressure or force against the unadepts. Rather they use specific schemes of closure. "Weber employed the concept of closure to refer to the monopolization of opportunities by various social groups. Social groups use power in order to maximize their own rewards and privileges by limiting the access to them. [3]" So this means the process of exclusion of other groups or persons.
Excluding others based on education and knowledge is the main instrument of such monopolization of activity. Well-taken description of this process is given by Larson: "Professionalization is thus an attempt to translate one order of scarce resources special knowledge and skills - into another - social and economic rewards. To maintain scarcity implies a tendency to monopoly: monopoly of expertise in the market, monopoly of status in a system of stratification. [9]" As Friedson shows one of the most important instruments of this process is the right of professions (for some of them established as legal order) to control the activities, to control the market through licenses and system of examinations and to monopoly educational system. Following this, professionalization process becomes the process of creation specific social groups which we could mark as reference social groups. Within these groups, current or on-coming members adopt particular ideology which is instrumental to exculpation as well as justification of their exclusive role on labour market and stratificational system of knowledge distribution.

It is approach toward ideology of professional groups in society that separate paradigms of structural functionalism from neoweberian approach. Structural functionalism does not question the ideology that stands against background of professionalism. It is accepted as an objective reality. For some authors, this approach is not a research on profession, but it is understood as an ideology of professions. Neoweberian approach, by contrast, connects the ideology of professionals with an excuse of the process of closure, separating professionals from unadept and not with an objective reality. Here, the ideology is understood to be collusion launched on laymen.

Thomas Brante offers elementary sets of distinctive types of self-legitimizing components that can be summarized under a number of sub - labels as follows:

1. The myth of technocracy - according to this philosophy the main factor of modernization of society is in field of technological innovation. Other factors, a political, cultural or ideological phenomenon, are irrelevant. And such a technocratic myth is essential to the profession; it justifies deviations from democratic principles, i.e. closures of public debates. "The more social problems that can be labelled as too complex for the citizen, the more constrained the sphere for public debates and democratic decisions becomes, resulting in more power and influence delegated to the expertise." [3]

2. The second important ideological myth about professional specificity is: The myth of certain knowledge. It is mean that professions differ themselves from other occupation groups in society through strong interconnection with sciences and systematical application of scientifically based knowledge to specific professional problems.

From the point of view of neoweberian approach, even if education and training for profession is led as scientific (medicine, law, engineering), the performance of professional role itself does not require such eligibility. "For instance, there is no logical con-

\footnotetext{
1) Symbolical interactionism is oficial name for one sociological theory (mead, blummer)
} 
nection between general scientific theories and professional practice. Scientific knowledge is not of the kind where you can deduce particular application from general principles. On the contrary it is most often the case that practice of professional is context-dependent i.e. solutions to problem are dependent upon general as well as specific knowledge and unique circumstances, social situation etc. [3]”

Another important attack against myth of certain knowledge is based on the social study of expert's controversies. This studies show that experts or professionals (engineers, economists, scientists, and physicians) have often different opposed conclusions upon the same problem even though they have access to the same facts. (for example High Tatra's problem). The most popular answer is that "general knowledge does not offer unambiguous answers, and therefore other variables (Political affiliation, ethical consequences, social aspects as family tradition and more others) are of influence when professionals make up their minds and suggest a particular route of action. [3]"

Other important parts of ideology of professions are as follows: the myth of neutrality, the myth of the hero, the myth of rationality and the myth of altruism. In all cases the neoweberian approach endeavours to question the ideology of professionals and to draw attention to its docility and falsity. Probably for that reason Brante names this approach as cynism. Within such frame individuals do nothing else but build their own influence, machinate other individuals and social groups to fortify its extraordinary position in society.

Of course, it seems as unsuitable to judge this approach to professions as absolutely wrong as it is quite applicable especially on lawyers or physicians. The problem is that it appears as rather not usable to the others. In contemporary society where the significance of expert's knowledge increases remarkably we can chance upon fact that its proprietors do not necessary create such profession groups as chambers of lawyers and physicians. They do not seek to monopolize certain stage of knowledge or praxis, and, as it can be seen on example of computer or programming technicians, expertness can be also created on the basis of unattached interest in given scope.

Increasing significance of expert's knowledge is accompanied by process of bureaucratization or rather by change in organizational structures of professions that undermines some Parsons' and Neoweberian assertions. We can find several examples of changing of organization structure in many works on professions [10].

Medicine - the primary norms and emphases of sector have shifted from access and quality issues to cost containment and service reduction (good example is transformation of medical system in Slovak republic).

Lawyers - are pressed to build up stables of clients and maximize billable hours, while the decisions making of judicatory is shaped by sentencing guidelines and tort law.
Engineers - are increasingly pressed to demonstrate the costeffectiveness of their design

Scientist - are expected to generate research grants as well as follow university and state plan for orientation of their scientific interests

Of course this is reduced enumeration of transformation of organizational background of professions. Processes of organizational transformation violate the conceptions of functionalists with the intent that professions do not represent subsystems of occupational system intended on universalistic goals that are supplied by internal social control (by professional ethical - ideology of professions). On the other hand, this transformation is good evidence of the fact that professions in "postindustrial society" are loosing their absolute dominance over role performance, as it expects neoweberian paradigm. They have to negotiate about it with other professions or better with other systems of expert knowledge. For example engineers, physicians, scientists have to coordinate their activities with economists, managers, environmentalists. And in recent years they have to do it with laymen (some environmental problems, genetic modified food etc.). Within the frame of traditional sociological point of view we can say that they try to support own definition of situation against others definitions.

\section{Possible approach to the professions}

Such process of loosing "pure professions ideology" from society is a good reason to looking for new explanations in this sphere of humans' activities. After us, we can use some concepts in contemporary sociology of scientific and expert knowledge (SSEK) (Knorr - Cetina, Konopásek, Latour, Law and Caloon). We attempt to introduce possibilities of this theory in following important events:

1. Instead of concept of profession that entails as positive (structural functionalism) as negative (neoweberianism) connotations it is perhaps better to use neutral term of expert's knowledge and praxis.

2. Different understanding of power - traditional understanding of power is based on its negative perception. The power excludes limits and destroys. Such perception of power is associated with its ideological and political status. Instead of such notion, protagonists of SSEK accept another and the one that is based on hypothesis that "power is an effect of network and result of collective action [11]". "Power is a consequence and not a cause of collective action [12]". This means power is not exclusive though it is result of enrolment of actors. For instance physicians do not control power because of achieving absolute separation from laymen. Rather contrariwise, they control the power because of being able to enroll and convince much of the unadepts who now follow the rules given by physicians. And this identifies the much of the expert's knowledge and praxis that can be also known as a result of creation of net of actors. It is, however, necessary to notice that power exists until enrolment of actors into the net is successful and thus keep the net stability. 
3. Who is an actor in the net? - This is exactly the point that makes elementary difference between "streamline" sociological approach and the SSEK. Traditional sociology would appear from the premise that power has respect to human beings. So individuals (human actors) are those that create nets that come to be the source of power. SSEK approach offers different explanation. The actor by himself is an element placed in heterogeneous net ac etiam a result of such heterogeneous net. Imagine the case of a programmer. It is created by enrolment so human as inanimate actors. Colleagues, friends, databases, software, computers and other hardware forms the enrolment of programmer into the net composed of heterogeneous elements [13]. Certain number of such elements should be activated or enrolled into the net to enable programmer to keep its stability.

4. Black boxing - is specific term used by SSEK approach. It is used to overmatch dividing into micro- and macro-spaces. Each actor, human or nonhuman, is created by heterogeneous net. While such net is stable this approach marks it as Black box. Black boxing is thereafter process that leads up to stabilization of the net. Individuals as well as complicated systems of science and industry can be perceived as "black boxes" with diverse intricacy of actors involved in heterogeneous net. And after this manner such expert's praxis as medicine, science or ITs can be also perceived. Medicine is relatively closing largescale black box that contains so human actors (physicians, patients, lawyers, politicians) as nonhuman (molecules, microbes, drugs, infections and so). All concerned are being drag into process of heterogeneous net formation. Such notion is applicable to, for instance, bridge construction. The bridge as such becomes black box as late as it really stands. In order to achieve this, it is necessary to create supportive heterogeneous net where engineers, banking houses, politicians, general public, building materials or biological actors are involved. Each of those actors, however, could possibly start creation of its own alternative network which is supportive to black boxing antiproject (revision of bridge construction). Let's say ecologists would attempt to involve general public, protected species or other expert's systems. For instance economists would attempt to involve different actors into their alternative network.

\section{Conclusion}

On terms of present circumstances, such approach seems to be instructive particularly because of mentioning contestations that expert's systems and praxis (among them professions also) need to deal with. On one hand, it is caused by specific uncertainty in face of science (Ulrich Beck's society of risks) and increasing number of expert's systems in society. Physicians, scientists, lawyers, engineers or managers need to work more against in order to create support for their intentions and goals while engaging much of heterogeneous actors (as good example can serve APVV's requirement that each project need to ensure publicity what means concerned enrolment of laymen into backing of science). We are conscious of our SSEK approach introduction is concise and simplifying though our main aim is to mention that some professions' transformations in postindustrial society can not be outlined by means of just traditional approaches.

\section{Referemces}

[1] BELL, D.: The Coming of Postindustrial Society, CAHOONE, L.: From Modernism to Postmodernism, Blackwell Publishers, Oxford, 1996, pp. 423-436.

[2] MACDONALD, K. M.: The Sociology of the Professions, SAGE Publications, London, 1995, ISBN 08039 86534-3

[3] BRANTE, T.: Sociological Approaches to the Professions, Acta Sociologica 2/1988, pp. 119-142

[4] KELLER, J.: Classical Sociological Theories, SLON, Praha, 2005

[5] Martin, D.: Modernization in Crisis - from Talcott Parsons to J. Habermas, Sociológia 3/1996, pp. 183-205.

[6] PARSONS, T.: The Professions and Social Structure, Social Forces 4/1939, pp. 457-467.

[7] PARSONS, T.: Essays in Sociological Theory, The Free Press, New York, 1964

[8] MERTON, R. K.: Social Theory and Social Structure, The Free Press, New York, 1968.

[9] LARSON, M. S.: The Rise of Professionalism. A Sociological Analysis, University of California Press, Berkeley, 1977

[10] LEICHT, K. T.; FENNELL, M. L.: The Changing Organizational Context of Professional Work, Annual Review of Sociology, 1997 (23), pp. 215-31.

[11] ZAMYKALOVÁ, L.: Identity in Net. Biograf 27, 〈http://biograf.institut.cz/clanky/clanek.pp?clanek=2712>

[12] MICHAEL, M.: Constructing Identities. The Social, the Nonhuman and Change, SAGE Publications, London, 1996

[13] LAW, J.: Notes on the Theory of the Actor Network: Ordering, Strategy and Heterogenity, Published by Centre for Science Studies, University of Lancaster, 1992, 〈http://www.comp.lancs.ac.uk/sociology/papers/Law-Notes-on-ANT.pdf> 